\title{
SOFT CONTEXTUALISM IN THE CONTEXT OF RELIGIOUS LANGUAGE
}

\author{
THORD SVENSSON
}

Lund University

\begin{abstract}
When trying to do justice to the discourse of a certain religion it is often implicitly assumed that one's analysis should accord with and respect the opinions held by the people preaching and practicing that religion. One reason for this assumption may be the acceptance of a more general thesis, that adherents of a given religious tradition cannot fail to know the proper content and function of the language and concepts constitutive of it. In this article, the viability of this thesis is explored through an investigation of the extent to which people belonging to a certain religion may be in error about what they mean. I assume that people, if mistaken, are wrong according to a standard which is mind-dependent enough for them to be committed and accountable to it but, at the same time, mind-independent enough for them to be mistaken about it. I try to account for this delicate balance by identifying the standard with a social norm, a mind-independent object of worship or people's intuitive judgement.
\end{abstract}

\section{INTRODUCTION}

To account for the content and purpose of religious language and concepts is an old and difficult task. Many have taken on themselves to present a proper account, but no one seems to have come up with a proposal which all or most people agree on. The objective of the following article is not to present such an account, but to examine some issues that need to be settled before any such account can be properly assessed. Most basically, how does one define and measure the accuracy of such an account? What facts should be considered and respected if one wishes to do justice to the language and concepts of a certain religious tradition? Must one's account, for instance, be accepted by the religious people who belong to the tradition? Or can one rather assume this to be less 
important, perhaps by thinking that the people may be mistaken about the content or function of the discourse constitutive of the religion they themselves preach and practice? ${ }^{1}$ If the latter, to what extent or in what sense may they be thought to be mistaken? In the following, a sequence of possible responses to this question is considered. Each response, except for the initial one, is presented as a development of the previous one.

I proceed as follows: In the next section, I attend to one specific aspect of D. Z. Phillips' position on how to analyse the content and function of religious language. In connection to this aspect, I put forward a distinction between 'soft' and 'strong' contextualism. Strong contextualism is the thesis that only people who belong to and practice a certain tradition or system, like a religious one, can make sense of the language and concepts employed within it; people outside the system or tradition cannot. Soft contextualism is the thesis that people who belong to and practice a certain system or tradition cannot be mistaken about the function and content of the concepts and language constitutive of it. The soft thesis states that people who use a certain language and certain concepts regularly and with serious intent know the proper function and content of these. The second of the two theses is the central focus of the present article, which mainly consists of an investigation of the viability of the thesis and of what reason one may have to adjust or reject it. Section III presents a preparatory analysis of what would constitute a justified rejection or qualification of the thesis, which brings forward the notion of a 'conceptual mistake.' In section IV I propose an 'anti-individualistic' construal of the thesis, which, when applied to the religious context, amounts to the idea that at least some members of a religious community know the proper function and content of the religious concepts and language used by most or all its members. In section $\mathrm{V}$ I examine the possibility of going beyond this proposal by exploring to what extent a whole community of religious people can be mistaken about what they mean in the sense of being mistaken about the nature of a mind-independent object of worship while yet referring determinately to it. In the last section, I continue to pursue this question

${ }^{1}$ By 'function' I mean for instance if the use of language is descriptive, prescriptive and so on. The question about the nature of the language, e.g. whether it is metaphorical or not, can also be tied to this functional aspect. 
by exploring in what sense people within the community can possess and employ a 'sortal' for the object of worship, which is required to refer to it, while being mistaken about the proper content of this sortal.

\section{SOFT AND STRONG CONTEXTUALISM}

People who study and analyse religious discourse naturally seek to do justice to its content and purpose. It is however not evident what it is to account for this aspect of religion or how it should be done. This circumstance may be exemplified by attending to what is often called a 'Wittgensteinian philosophy of religion' and the discussion it has aroused. One distinguishing and well-known feature of this Wittgensteinian position is the claim that many religious people and scholars have failed to appreciate what religion and God-talk are all about. They have missed the distinctiveness of religious concepts and have not realized that the content and function of these are not the same as for concepts used in different, non-religious, contexts. D. Z. Phillips, as is well known, was one who persistently argued this to be the case. ${ }^{2}$

A common response to Phillips' charge is that, to the extent that such an interpretive mistake has been made, it is rather Phillips and people accepting his account who are the ones guilty of it. They are the ones who misrepresent the content and purpose of religious language and concepts. To back this up, one usually appeals to the fact that many religious devotees do not appear to feel quite at home with Phillips' account of what they mean. This, it is argued, must definitely rule out Phillips' analysis. For instance, not so long ago John Hick wrote:

In the end, Phillips was implying that religious people don't mean what they say, but that he knows differently and better than them what they must mean. This constitutes a fundamental flaw in his philosophy of religion: he both appealed to and yet contradicted the use of religious language by devout religious people. He based his case on the actual use of religious

${ }^{2}$ For a good presentation of this circumstance, see Richard Messer, Does God's Existence Need Proof? (Oxford: Clarendon Press, 1993), 49-50. For a more recent and very thorough exposition of Phillips' approach, see P. F. Bloemendaal, Grammars of Faith: a Critical Evaluation of D. Z. Phillips's Philosophy of Religion (Leuven: Peeters, 2006). 
language by religious people, within their form of life, but rejected their own understanding of what they are doing. ${ }^{3}$

According to Hick, one cannot do justice to a religious language while disqualifying the account of it presented by people seriously engaged in it. This is, however, precisely what Phillips, in Hick's eyes, is doing and what disqualifies his analysis. In responding to this criticism, Phillips does not so much object to this description of what he does as he questions what's wrong with it. Phillips writes that:

[T] he account given by a believer has no automatic philosophical warrant. It, too, must be conceptually faithful to the belief. If we say, 'Who better to ask than the believers?', we should reflect on the fact that if we asked 'thinking people' to tell us what they mean by 'thinking,' a confused Cartesianism would be returned with a thumping majority. We cannot do philosophy by Gallup poll. Religion like, 'thinking,' can be the victim of widespread friendly fire. ${ }^{4}$

In doing conceptual justice to religious language one cannot then, according to Phillips, rest one's case on what the people employing it are thinking about it because they may also be mistaken about its proper function or content. In reasoning like this, Phillips may be held to object to two theses, what I call soft and strong contextualism. Strong contextualism is the idea that only people belonging to a certain religious tradition or community can understand the proper content and function of the concepts and language employed within it. People outside the community or tradition cannot do this to the same extent. ${ }^{5}$ Even if

${ }^{3}$ John Hick, “D. Z. Phillips on God and Evil," Religious Studies 43 (2007): 440.

${ }^{4}$ D. Z. Phillips, "Pictures of Eternity - A Reply to Mario von der Ruhr" in D. Z. Phillips' Contemplative Philosophy of Religion: Questions and Responses, ed. Andy F. Sanders (Aldershot: Ashgate, 2007), 78. Phillips is not responding directly to the passage quoted from Hick.

${ }^{5}$ As is well known, Phillips is often attributed this position. Mark Addis seems to think that Phillips is a 'fideist' and then explains fideism as the position that '[R]eligious language is intelligible only to those who participate in the religious form of life. [...] Religious language constitutes a distinct linguistic practice which non-participants in the form of life could not grasp and show to be incoherent or erroneous.', see Mark Addis, “D. Z. Phillips' Fideism in Wittgenstein's Mirror" in Wittgenstein and Philosophy of Religion, ed. Robert L. Arrington et al. (London: Routledge, 2001), 85. To the extent that 
one is sceptical of strong contextualism, one may still accept that people who preach and practice a certain religion know or establish the content and function of the main concepts of that religion. That is, one may still find it reasonable to assume that people employing a certain language and certain concepts regularly and seriously are in a good position to know the function and content of the language and the concepts, for how else are they, for instance, able to operate with them confidently and seemingly accurately? To accept this idea is to accept the thesis of soft contextualism. Soft contextualism does not entail that people "outside" the religion cannot come to know the proper function and content of the concepts and language used within it, only that people "inside" the religion cannot fail to. If one accepts this thesis, one may draw upon it to argue that a philosophical analysis of what the concepts within a certain religion mean should agree with and respect the opinion about this matter held by people belonging to that religion. This is one important motive for exploring the nature and intelligibility of soft contextualism. As we have seen, when trying to do justice to religious concepts, Phillips, for instance, thinks that the religious people employing the concepts can be mistaken or ignorant about what they actually mean. It is in virtue of this that I regard him as an opponent, not only to strong contextualism, but also to soft contextualism.

In what follows, I will focus on soft contextualism. The reason for this is that the principle idea of soft contextualism has not been the subject of as much discussion and investigation as the principle idea of strong contextualism, nor has it been investigated to the degree it deserves. Our investigation of soft contextualism will, however, also be relevant for anyone interested in, or even defending, strong contextualism. If we, for instance, as a result of the impending investigation, were to become sceptical of soft contextualism, we would also seem to have a reason for doubting the intelligibility of strong contextualism. It would for instance be difficult to maintain that only people belonging to a religious tradition can know the proper content of the concepts employed within it (which is the thesis of strong contextualism) if they can be mistaken about the

Addis suggests that Phillips thinks that only religious people can understand the proper meaning of religious language, I think Addis is wrong. Apart from the fact that such an idea would appear to be in direct opposition to Phillips' criticism of soft contextualism, the textual evidence for thinking that this is not Phillips' position seems quite extensive. 
content (which a rejection of soft contextualism would imply). It has been helpful to consider Phillips' position in explaining soft contextualism. However, in exploring the intelligibility of this thesis, I proceed without focusing especially on his position as I wish to approach the matter from a more general perspective.

\section{THE VIABILITY OF SOFT CONTEXTUALISM. - A PRELIMINARY ANALYSIS}

We should begin our investigation of soft contextualism by initially making clear what would motivate a rejection of it. That is, what would qualify as an instance of people being ignorant or mistaken about the content of the concepts and language they employ? I will propose and in the following work with the idea that one distinguishing feature of such mistakes, which I call conceptual mistakes, is that people who are guilty of them are mistaken according to a standard for correct thinking about the language and concepts they employ which they hold themselves committed and accountable to. The possibility of such mistakes presupposes a delicate balance. The standard in question should be objective and mind-independent enough for them to be able to be mistaken about it, but subjective and mind-dependent enough for them to be accountable and committed to it, to be what they "actually" mean or should mean. Before we begin to examine if people may be guilty of conceptual mistakes, let us attend just a bit more to why this is a relevant question to consider. The idea of a conceptual mistake, if sensible, can help us account for how we may criticise a religion from within the religion itself, by for instance claiming that certain rituals or beliefs are not doing justice to the standard implicit in and constitutive of that religion and which people, in virtue of believing in it, may be held committed and accountable to. For this reason, one can also draw upon the notion of a conceptual mistake to question a too simple distinction between 'prescriptive' and 'descriptive' accounts of a religious tradition. Accounts not directly in line with the ordinary and commonly accepted interpretation of a religious tradition are often considered prescriptive or revisionary ones. The notion of a conceptual mistake may cast doubt on the legitimacy of this tendency. 
Let me also make clear what seems to be the main problem in establishing a conceptual mistake: The fact that people usually seem to be committed to a standard by knowing it. If this is true, one can surely wonder how people can be committed to a standard while being mistaken about it. We may phrase the problem with regard to concepts: To possess a concept is often equated with knowing how one should employ it. In showing that people can make conceptual mistakes, we thus need to show how people can know enough to possess and to be committed to a certain concept while, at the same time, know too little to have infallible knowledge about its proper function and content.

\section{A SOCIAL MODIFICATION OF SOFT CONTEXTUALISM}

How, then, can one commit a conceptual mistake? One initial possibility would be to accept the anti-individualistic proposal that a person can possess a concept, even when having a partly mistaken or incomplete account of it, in virtue of belonging to a community of people in which at least someone has a complete and accurate account of it. One wellknown defender of this proposal is Tyler Burge, who argues that people should be thought to possess the common concept of, for example, a contract even when, for instance, thinking that an oral agreement does not constitute a binding contract. If many enough of the beliefs they have about the concept of a contract are accurate, they should be thought to possess our ordinary concept of it rather than a personal and deviant one. It would then also be correct to describe what they mean and what beliefs and thoughts they have by relying on the ordinary concept. It would for example be correct to state that 'Susan thinks that she just signed a contract,' even if her idea of a contract is incorrect. Of course, what is true for the concept of a contract is also held to be true for many concepts. ${ }^{6}$ What concept a person has is thus not settled by and limited to what she has in 'her head,' that is, what she believes the proper content is. What someone has in 'her head' may also not settle what she can refer to. To consider a well-known example from Hilary Putnam, a person

${ }^{6}$ See Tyler Burge, "Individualism and the Mental" (1979), in Foundations of Mind, Philosophical Essays, vol. 2, ed. Tyler Burge (Oxford: Oxford University Press, 2007), 105-7. 
can be judged to refer determinately to elms even though he does not know how to distinguish an elm from a beech. ${ }^{7}$ As long as the person is a member of a community of people in which someone else is able to tell them apart, he can rely on that person's expertise.

A person can then possess a concept while being mistaken about its content because she may not only possess the concept in virtue of having an accurate or complete account of it. She can also possess the concept in virtue of having an accurate enough account of it and by being a member of a community of people in which some people have a full and correct account of it. What concept she has and is committed to thus depend on what community she belongs to. Being a member includes being committed and accountable to the communal norm for the concept, which is the same as what better informed people accept as the proper content for it. ${ }^{8}$ One reason for accepting this account of concept-possession is that it seems to do justice to our ordinary practice of concept-attribution and our commitment to a socially shared and accepted norm for thinking about the world. If we adopt this picture of what it is to have and employ a concept and to be committed to a standard for proper thinking about its content, we seem to have some reason for questioning soft contextualism because according to this picture, people may have a concept without having a proper account of it. We also realise that one possible reason for assuming the correctness of soft contextualism from the outset is that one adopts an individualistic theory of language-use and concept-possession. Recall, one common argument for soft contextualism is the idea that a person possesses a concept in virtue of knowing its content, for what else explains how he can operate with it? In drawing upon the social nature of language-use and conceptpossession, anti-individualism requires less from an individual user of a language and concepts.

${ }^{7}$ Hilary Putnam, “The Meaning of "Meaning"' (1975), in The Twin Earth Chronicles: Twenty Years of Reflection on Hilary Putnam's "The Meaning of 'Meaning”, ed. Andrew Pessin et al. (New York: M. E. Sharpe, 1996), 12-14. Putnam calls this 'division of linguistic labor'.

${ }^{8}$ Burge thinks that 'Speakers commonly intend to be interpreted according to standards of usage that are in some respects better understood by others', see Tyler Burge, "Social Anti-Individualism, Objective Reference," Philosophy and Phenomenological Research 67 (2003): 684. 
Of course, an advocate of soft contextualism may not regard antiindividualism as an accurate explanation of concept-possession and may simply refuse to acknowledge it. A more interesting response, and one that I will focus on, is the idea that anti-individualism does not so much call into question the doctrine of soft contextualism as it points to a sensible modification of it, or maybe a qualification of it assumed from the outset. Applying anti-individualism to, for example, a certain religious community would just mean that at least some people within the community know the proper function or content of the religious concepts or language used by most or all people within the community. As long as soft contextualism is not construed as the thesis that everyone who belongs to a certain community knows the content of the concepts and language employed within it, anti-individualism seems compatible with it. And in doing justice to the content and function of the concepts used within a community, it is thus enough that one's analysis is consistent with the opinion of some of its members, perhaps the ones considered to be authorities concerning what the concepts in question mean.

We can exemplify this version of soft contextualism by attending to what can be called 'traditional theism', the religious worship of a transcendent subject, wholly or partly responsible for the creation and destiny of mankind. Let us assume a community of people preaching and practicing such theism. We may then propose that in order for soft contextualism to be true of such a religious community, the following must be true of it: (1) at least some people within it must know what they all mean and refer to by 'God' and related concepts and (2) the rest of the people can be less knowledgeable although competent enough to defer to the former group of people, in order to "mean what they mean." Such a religious community may be held to exemplify a 'communal' or 'social' type of soft contextualism.

\section{ON THE POSSIBILITY OF A WHOLE RELIGIOUS COMMUNITY BEING MISTAKEN}

We ended the last section by construing a version of soft contextualism that defused the anti-individualistic objection to it, by making soft contextualism compatible with it. Is this then the end of the line? Have 
we pushed our scepticism of soft contextualism as far as possible or may we push it just a little bit further? In exploring this matter, it seems natural to consider the possibility of a whole community of people, and not just some members of it, being mistaken about what they mean. The idea is not that everyone in the community must be mistaken about the content of a certain concept or word; perhaps not all people within the community employ it. We are rather wondering if it is possible for people to be incorrect concerning what they mean without being wrong relative to the standard set by someone else in the same community. The possibility of this being the case seems to presuppose a standard that everyone can be committed and accountable to while yet being mistaken about it. How may this come about? In trying to account for this delicate balance, one suggestion may be that the standard for what they mean by a certain concept or word is a mind-independent object referred to by the people. In virtue of being mind-independent, it would account for the required distance between it and the people for the people to be mistaken about it. Relating this to theism, we can equate the mindindependent object with the theistic God and suggest that people within the theistic community are committed to this object by referring to it. The relevant question would then be - to what extent and in what sense can the whole community be referentially committed to a possible God while having mistaken beliefs about its nature?

According to one traditional theory, religious people succeed in referring to God in virtue of having an identifying description of God. The description does not need to be complete but it must be correct and precise enough to pick out God. Without going into the details of this theory, which can be construed and interpreted differently, it seems to entail that the possibility for a community of people to refer determinately to God while being radically mistaken about God's nature is rather limited, due to the fact that they refer in virtue of knowing a true enough description of God. That is, if what they hold to be true of the object of worship is not uniquely true, or true at all, of it, one may claim that they either refer to something else (the object fitting the description) or nothing at all (if nothing or too much fits the description). The people may still be moderately mistaken about the nature of God but not to the extent that the identifying description of God is abandoned. We thus seem to have reached some conclusion regarding how mistaken a community 
of religious people may be about what they mean. However, since this conclusion is relative to a certain theory on how religious people refer to the object of worship, one may of course wonder if this theory is the only game in town? Or may we adopt a different theory on how people refer to God which does not demand that they have a correct account of the object of worship?

The most natural option may be what is usually referred to as the 'causal' theory of reference developed by and mainly associated with Saul Kripke, Keith Donnellan and Hilary Putnam. ${ }^{9}$ One general idea argued for in the name of this theory is that one does not refer to an object in virtue of having an accurate or identifying description of it because one can be held to refer successfully to it although one's description is not uniquely true, or true at all, of the object. With regard to how a proper name refers, Kripke, for instance, thinks that the name is initially attached to its bearer through a naming ceremony. People not attending the event, most people that is, can still refer to the individual given the name in virtue of intending, by the name, to refer to the same person as the one they got the name from or "everyone else" (if they have forgotten who they got the name from). The person they got it from, or "everyone else," in turn, has the same intention towards someone else and so on, creating a connection from the present user of the name back to the people at the naming ceremony. It is this link-to-link connection that usually lets us refer to a certain person although we may know very little about him or her. According to this idea, 'Aristotle' does not refer to the famous philosopher in virtue of the descriptive content associated with his name. This entails that 'Aristotle' would refer to the same person even if most of our beliefs about him turned out to be mistaken, that he, for instance, was not the author of On Interpretation and the Metaphysics.

More or less orthodox versions of the causal theory of reference have been used to account for how religious people refer to the object of worship. Drawing upon Putnam's, Kripke's and Donnellan's criticism of the descriptive theory and by assuming that we can refer to an object by describing its causal effect rather than knowing its true nature, Janet

9 See for instance Keith Donnellan, "Speaking of Nothing," The Philosophical Review 83 (1974): 3-31; Hilary Putnam, "The Meaning of "Meaning"'”; Saul Kripke, Naming and Necessity (Oxford: Blackwell, 1981). 
Martin Soskice thinks that we can refer to God, even if we are very ignorant or mistaken about God's nature.

To employ an argument analogous to that which we have employed in the scientific case, we must claim to point to God via some effect and a more satisfactory way of doing so is to follow the more experiential lead of Aquinas and say that 'God is that which is the source and cause of all there is.' This does not demonstrate that there is a unified source nor that, if there is, it meets any description preferred by theists. As in the scientific case, to be a realist about reference is to be a 'fallibilist' about knowledge of the referent. Speakers may refer and yet be mistaken, even quite radically mistaken, as to the nature of that to which they refer. ${ }^{10}$

In a similar fashion, building extensively on Kripke's reasoning about how a proper name refers, William Alston argues that the referent of 'God' is picked out through a religious experience: 'God' refers to whatever some people come to face through that experience and people who have not had such an experience may defer to the ones who have. 'God,' then, does not refer in virtue of the descriptive content often associated with it. The object of the religious experience may not fit the descriptive content. In fact, the content can fit a different object not experienced by the people using the name. The object experienced is nonetheless what we refer to by 'God.'

If we accept the causal theories suggested by Soskice and Alston on how people can refer to God, they entail that a religious community can be rather mistaken about the object of worship. This, in turn, would mean that our previous conclusion concerning how mistaken people can be about a possible God while still referring to it, based on the descriptive theory, must be modified. To bring out the difference between the two theories, assume that the descriptive content associated with 'God' within a certain theistic community does not apply to the entity causally responsible for the creation of the universe. Perhaps the property 'all-

${ }^{10}$ Janet Martin Soskice, Metaphor and Religious Language (Oxford: Clarendon Press, 1985), 139. Soskice argues for a modified version of the causal theory by thinking that senses of words do matter, although not in the sense usually associated with the descriptivist theory. See Soskice, Metaphor, 132.

${ }^{11}$ William Alston, "Referring to God," International Journal for Philosophy of Religion 24 (1988): 118-122. 
knowing' is not true of the entity. If we were to rely on a descriptive theory, we may then be forced to conclude that the people have not referred to this entity and since they have not referred to it, they cannot be held to be mistaken in relation to it. On a causal theory, in contrast, we would not be forced to draw this conclusion. On both theories, an entire community of religious people may be mistaken about God's nature, but on the causal theory, the mistakes, it seems, can be rather big.

If we were to accept a causal theory of reference in the context of God-talk, the outcome of it would not appear unimportant. It would for instance offer a theist the possibility to substantially change her religion without her changing religion because what establishes the identity or continuity of the theistic religion is the divine subject referred to and, according to the current approach, the theist can remain referentially committed to this subject even when radically changing her beliefs about its nature. More precisely, the causal theory would, for example, provide a feminist minded scholar or devotee the ground needed for claiming that a removal of the masculine gender used in much theistic God-talk does not change what theists have been referentially committed to all along. Another outcome that is interesting with regard to the matter of soft contextualism is that people may not only be radically mistaken about the nature of what they refer to while still referring to it, but also about how they refer to it, for instance by incorrectly believing that some description of God is fixing the reference for 'God' while this, in fact, is not so. I return to this specific outcome in section VI.

One may however argue that the causal theory may fail to account for what a theist refers to by 'God.' The reason for this failure is that the information and procedure it relies on to pick out the object of worship is too imprecise. To exemplify this, suppose a person declared that God is 'whatever was causally responsible for me having a certain religious experience.' Is this account sufficient to make that person refer determinately to God? To some extent this will depend on what we mean by 'refer determinately', but one may claim that the account 'God is whatever was causally responsible. . ' is too thin to do justice to what theistic people intend to refer to by 'God.' They do not identify God with whatever was causally responsible for some religious experience. For this object to be considered God it must be a certain kind of object and not just any kind of object. Perhaps it must be spiritual rather than material 
and maybe also personal. If the object does not have such features it is not God. ${ }^{12}$ To account for what people within the theistic community have referred to, we may thus have to accept that for an object to be considered God, it must fit a certain category, or set of categories. The category or categories may not be unique for the object. Let us call such a category or set of categories a God-sortal. The God-sortal then determines the extent to which theistic people can be wrong about a possible object of worship while still referring determinately to it. An entity, even if causally responsible for a religious experience, which does not fit the God-sortal, cannot be considered the proper referent - God that is. ${ }^{13}$ Of course, the sortal alone would not be enough to account for what theistic people refer to by 'God.' To the extent that we accept the causal theory in this context, the sortal should be regarded as an important complement to it. ${ }^{14}$ People committed to a God-sortal seem to be committed and accountable to something less than an identifying description of the object of worship, but to something more than a 'causal description,' like 'God is whatever was causally responsible for me having this religious experience.' Recall, the general purpose of this whole discussion is to try to establish to what extent a mind-independent object of worship can constitute a standard according to which religious people can be mistaken about what they mean. Perhaps then the proper response to this question is: To the extent that the mind-independent object of

12 See for instance Michael Durrant, "Reference and Critical Realism," Modern Theology 5 (1989): 139-140; See also Peter Byrne, Prolegomena to Religious Pluralism (London: Macmillan Press, 1995), 45, 51 for a similar idea.

${ }^{13}$ We may perhaps exemplify the idea of a sortal by returning to our previous example with Aristotle. Although we may accept that 'Aristotle' would still refer to Aristotle even if it was discovered that he was not the author of On Interpretation or the Metaphysics, or perhaps any philosophical text, we would not, I think, be quite as open-minded if we discovered that 'Aristotle' was in fact the name of a cat. The reason for this, I suggest, is that a cat is not the kind of being we intend to refer to by 'Aristotle.' A cat does not fit our sortal for 'Aristotle.'

${ }^{14}$ By introducing the idea of a 'God-sortal' I do not wish to engage in a metaphysical discussion about God's nature by for instance opposing the idea that God does not belong to any genus. I am only attending to what people commonly hold to be essential for God, that is, what they think an object must be like to qualify as God and to be the object they have intended to refer to. The current suggestion, that for an object to be God it must be of a certain kind, is intended to capture this attitude of many religious people and thinkers. Of course, the precise content of the God-sortal can be discussed. 
worship fits the sortal associated with it. We thus seem to have reached some conclusion about just how mistaken a whole community of theistic people may be about what they mean.

\section{ON THE POSSIBILITY OF BEING MISTAKEN ABOUT THE GOD-SORTAL}

Have we then, at last, come to the end? Have we come to a conclusion about the extent to which people of a theistic community can be mistaken about the object of worship and still refer to it? It surely appears so. Recall that to commit a conceptual mistake is to do wrong according to a standard one can be held to be committed to. If the standard is a mindindependent object, one must be referentially committed to it and this appears to presuppose that the object fits our sortal for it. The sortal thus determines how mistaken people may be about what they mean, 'mean' in the sense of what they refer to. Still, one cannot help but wonder if it would be possible for people to possess and employ a God-sortal while being mistaken and ignorant about its true content. In this last section, I consider this possibility.

To know the sortal for the object one refers to is to know what kind of object it is. Drawing upon this account of the sortal we can reconnect to the Wittgensteinian tradition, attended to in section II, and its idea of 'depth grammar' since 'grammar tells what kind of object anything is.' ${ }^{15}$ Simplifying the concept of depth grammar somewhat, the basic idea seems to be that for a certain sort of object, we have a 'grammatical rulebook' establishing what would be sensible to claim and think about it. For instance, to assert that a certain person is in a good mood is sensible, regardless if it is true or not since 'being in a good mood' is a property that may properly be attributed to a human being. In contrast, to declare that the tree outside my office has had a bad day and is looking forward to tomorrow is neither true nor untrue, just nonsense; a tree does not look forward to anything. We may connect this to Putnam's example with elms attended to in section IV. A person may be held to refer to

${ }^{15}$ Ludwig Wittgenstein, Philosophical Investigations, trans. G. E. M. Anscombe (Oxford: Blackwell, 1953), paragraph 373. 
elms even if he does not know the precise difference between elms and beeches, but if he does not even know what a tree is, what kind of object it is, he can be held to be too ignorant to refer to elms; he then lacks knowledge of the sortal/grammar for the object he intends to refer to.

Remember, Phillips thinks that religious people can be mistaken about what they mean. His position is complex and heterogeneous but one core idea is certainly that what religious people claim and think may not make sense relative to the grammar for the concepts they employ and the objects they refer to. With regard to this, but also with regard to the specific need for a God-sortal in the case of referring to God, one may wonder if people can be mistaken or ignorant about the sortal or grammar for a certain object. That is, can they be mistaken and ignorant about what they themselves consider to be the God-sortal? For people to be mistaken or ignorant in this sense, they should be wrong relative to a standard they hold themselves committed and accountable to. As previously assumed, for people to be mistaken and ignorant in this sense, the standard must be mind-independent to some extent, in order to account for how they can be mistaken about it, but not too mind-independent, because that would make it hard to hold the people accountable and committed to it. We thus need to ask: Does the possibility of such mistakes extend to how religious people have and know a God-sortal?

One idea would be to distinguish between implicit and explicit knowledge of the God-sortal. In presenting this option, we can attend to one contemporary theory on conceptual mistakes and analysis. Frank Jackson thinks that when we are being presented with a "Gettier-case" and through this come to question our old and traditional definition of knowledge, we do not seem to conclude that we have been misapplying the concept of knowledge and that we need to change our use of it. Rather, we seem to think that the common definition of knowledge as 'justified true belief' does not capture what has been implicit in our actual employment of the concept all along. In this we have a conceptual mistake rather than a conceptual change because we hold ourselves committed and accountable to how we employ a concept rather than to how we define it. ${ }^{16}$ According to this position, people can possess a concept by knowing

${ }^{16}$ Frank Jackson, From Metaphysics to Ethics: A Defense of Conceptual Analysis (Oxford: Oxford University Press, 1998), 36, 38. 
how to categorize certain objects as being of a general kind. They can for instance be able to identify certain objects as tables, although not being able to explicitly account for how they do it. As Christopher Peacocke puts it: 'thinkers can be good at classifying cases, and bad at articulating the principles guiding their classifications. ${ }^{17}$ People may thus be unable to present a definition of the concept of a table or what rule they follow in categorising tables as 'tables.' They may of course have an idea about what the proper content of the concept of a table is, but, according to the current theory, they do not possess the concept of a table in virtue of believing in a certain, correct or incorrect, definition of it; much in the same sense as people, according to the causal theory of reference, do not refer to an object in virtue of having an accurate account of it.

If we accept this idea about what it is to have a concept, we can draw upon it to argue that religious people may be employing and committed to a certain God-sortal, while being mistaken about its precise content. If we agree on this, we also have a reason for questioning the specific version of soft contextualism previously considered, that people cannot use and be committed to a certain God-sortal while failing to know its true content. Once more we also come to challenge one general motive for soft contextualism, the idea that one has to know a concept properly to be thought to possess and employ it, for how can one use it intelligibly or successfully if not by knowing its content? To the extent that such knowledge is thought to be explicit, it does not, in fact, seem to be required. We may also perhaps obtain support for Phillips' conviction that one can do better justice to a certain religious concept by focusing on how it is used rather than on how its content and function are described by the religious people using it. Moreover, although we are drawing upon the distinction between implicit and explicit content of a concept to show how a person can be mistaken about the proper content of his own God-sortal, we may extend the distinction beyond this particular case to other religious concepts. We can then account for how a whole community of religious people can be mistaken about what they mean by the concepts they employ without appealing to a mind-independent object. Instead we can appeal to a "mind-independent" content of the

${ }_{17}$ Christopher Peacocke, "Implicit Conceptions, Understanding and Rationality," Philosophical Issues 9 (1998): 51. 
concepts, mind-independent in the sense of not being explicitly known. This may be an important outcome in that many religious concepts do not pick out a mind-independent object or subject in the same sense that the concepts of a tree, gold or God may do.

Still, one may think that the possibility of being mistaken in the manner currently considered does not apply to every concept. This might be correct. As Paul Grice once remarked, it does not appear possible to know or have the concept of a father without knowing what a male parent is, although one can have and employ the concept of awe without knowing or agreeing upon the conventional definition of it, a 'mixture of fear and admiration.' ${ }^{18}$ The distinction between knowing a concept implicitly and explicitly does not seem to apply to the concept of a father because if we change the explicit account of what we mean by 'father' (male parent), we also change the concept. Perhaps one wants to draw upon this possible limitation of the distinction between implicit and explicit knowledge of a concept and claim that the distinction doesn't apply to the God-sortal or the context of religious concepts in general. If true, this would entail that the current criticism of soft contextualism, drawing upon this distinction, may not extend to the religious version of soft contextualism currently considered. How, then, can one settle if it does apply to the religious case or not?

Perhaps one can propose that the distinction primarily applies to concepts the content of which we may typically be uncertain about, such as 'time' or 'personal identity'. If one accepts this, admittedly imprecise, criterion for when the distinction applies, one can argue that the Godsortal and religious concepts in general are unaffected by it in virtue of not being among the concepts we usually wonder about. Alan Bailey, for instance, seems to accept this latter idea.

We normally have no difficulty, for example, in telling other people what time it is or how much time a particular activity is likely to take. However when we stand back from such mundane activities and ask ourselves 'What is time?', we are suddenly plunged into confusion. In the case of religious discourse, though, this phenomenon is almost unknown. If someone who is at ease using the word 'God' in prayer and catechisms asks 'What is God?',

${ }^{18}$ Paul Grice, "Postwar Oxford Philosophy" (1956), in Studies in the Way of Words, ed. Paul Grice (Cambridge, Mass.: Harvard University Press, 1989), 176. 
that person rarely has any difficulty in arriving at an answer with which he or she is fairly comfortable. ${ }^{19}$

I disagree with Bailey. Just like people will have a hard time, not in saying what time it is, but in saying what time is, I think that religious people can initially find it easy to talk to or about God, but difficult to make sense of the concept of God if asked about it. And even if they are not uncertain or confused about what they mean from the outset, it does not appear all that difficult to make them wonder about it. Of course, we do not seem to be confused or uncertain about the proper content of all concepts, but the distinction between confusing and non-confusing concepts doesn't coincide with a distinction between religious and nonreligious concepts. Moreover, it also appears difficult, if not impossible, to separate religious and non-religious contexts and concepts. For instance, if our concept of time is a confusing one (as Bailey appears to think), so must the concept of God (as a being outside time) be. So even if people may not be mistaken or ignorant about all concepts they employ, this fact would not by itself entail that religious concepts are not among the perplexing ones. The current criticism of soft contextualism, drawing upon the distinction between implicit and explicit knowledge, thus appears to apply to the notion of a God-sortal and the context of religion in general. At least we have seen no reason for why it should not be thought to do so. Religious people can thus be mistaken about the God-sortal along the general line suggested so far in this section.

However, the present suggestion about how religious people can be wrong concerning the God-sortal may also be used to defend a different kind of soft contextualism, one drawing upon the notion of intuitive judgement.' People within a religion who may be ignorant about the proper and implicit content of a religious concept, like the God-sortal, can still be held to have an intuitive account of it. One reason for thinking so is the following picture of what is going on:

According to a widely held view, when philosophers analyze a concept they are seeking an explicit account of the concept's content - a content that they

${ }^{19}$ Alan Bailey, "Wittgenstein and the Interpretation of Religious Discourse", in Wittgenstein and Philosophy of Religion, ed. Robert L. Arrington et al (London: Routledge, 2001), 135. 
already know in some implicit manner. This implicit knowledge provides the intuitions that guide us in formulating proposed analyses, and allows us to recognize counterinstances to these proposals. Our inability simply to state the correct analysis is explained by this distinction between the implicit knowledge we already have and the explicit knowledge we seek. ${ }^{20}$

One can, then, argue that when working out an analysis of a certain religious concept, one should consider our intuitive judgement about it, because this is believed to reveal what we implicitly know about it, and what we thus hold ourselves accountable to. One may also claim that it would be peculiar if people employing a concept on a regular basis had no firm and reliable intuition about its proper content. That would seem peculiar in that our intuitive judgements must have a source. They don't come from nowhere, and it would appear natural to think that when we reflect intuitively about the proper use or content of a concept, what we do is to abstract information from our actual employment of it. This appeal to intuitive judgement would lead us back to a certain kind of soft contextualism, one consisting of the idea that people using a certain concept regularly and seriously cannot fail to have a reliable intuitive judgement about its proper content. It may not be easy for them to figure out the proper content, but also not impossible. Interestingly enough, the current suggestion also seems to lead back to an 'individualistic' kind of soft contextualism in that people's implicit and intuitive judgements do not depend on or defer to someone else within the community they belong to. The suggestion can also perhaps account for how religious people can be justified in opposing Phillips' account of what they mean: Even if they can be wrong about the God-sortal or the grammar for some object, they cannot be too wrong about this while being committed to it, and the devotee's intuitive judgement about this determines the extent of her commitment, and thus how mistaken she may be.

Have we, then, finally come to the end in our investigation of the nature and status of soft contextualism? Does our intuitive judgement about a concept constitute the norm for accurate thinking about it, which we hold ourselves committed to and according to which we may be wrong? One reason for thinking so is that it appears difficult to go

${ }^{20}$ Harold Brown, "Why Do Conceptual Analysts Disagree?"' Metaphilosophy 30 (1999): 33 . 
beyond intuitive judgement. For instance, even someone arguing for the causal theory of reference, and who perhaps claims that what we "have in mind" when referring is less important than usually assumed for us to be successful in this, may nonetheless be thought to base his argument on an intuitive idea about what it is in virtue of which people refer to a certain object. ${ }^{21}$ The criticism of a certain religious kind of soft contextualism, the view that people cannot be mistaken about God beyond an identifying description of God, may thus depend on the accuracy of a different kind of religious soft contextualism, the view that a religious person cannot be mistaken beyond his or her intuitive judgement about the God-sortal. We thus appear to have come to the end of the road, but in some sense perhaps also just the beginning of it, because the notion of intuitive judgement raises many questions. To end this article, I only want to point out one of them.

One question concerning this matter is: is an intuitive judgement what constitutes the proper content of a concept or is it our evidence in figuring this out? To the extent that we accept the former option, we have a reason for thinking that religious people cannot be very wrong about what they mean in that what they intuitively judge themselves to mean is constitutive of what they mean. One problem with this option is that if someone was to change his intuitive judgement, he would then automatically change his concept; or if people within the same religious tradition were to differ in what they find intuitively correct, they would, it seems, have different concepts. This may seem incorrect in that it would appear to make conceptual change and diversity all too easy to come by. To avoid this outcome, one can soften the relationship between a concept and our intuitive judgement about it by regarding the latter as evidence for what we mean by the former; as information in need of assessment rather than conclusive and infallible knowledge about the concept's content. However, if we accept this "evidential" reading of intuitive judgement, we appear to reopen the matter explored throughout this article. Once more we seem to accept that we can be ignorant and mistaken about what we mean due to the fact that an intuitive judgement is inconclusive or can be interpreted wrongly. If so, then we need to

${ }^{21}$ See for instance Frank Jackson, "Reference and Description Revisited," Philosophical Perspectives 12 (1998): 213 for this idea. 
examine to what standard an intuitive judgement is accountable and according to which it can be judged correct or incorrect. This is surely an important and interesting question and I hope to be able to return to it another time.

Throughout this article I have sought to show some of the different senses in which religious people can be mistaken about what they mean. In closing, I should emphasize that I do not, of course, think that I have offered a complete investigation of this matter; much more should be said about each of the senses attended to. Nor do I wish to imply that only religious people may be mistaken in the senses considered. I do, however, consider the religious context as one of the most interesting ones, if not even the most interesting one, for pursuing questions about the sense in which or the extent to which people can be ignorant about what they mean. Hopefully I have made some contribution to showing how this can be and why. 